\title{
PERUMUSAN PREMI BULANAN ASURANSI KESEHATAN INDIVIDU PERAWATAN RUMAH SAKIT (ANUITAS HIDUP PEMBAYARAN BULANAN)
}

\author{
Agustina Paula Theresia Putri lahallo ${ }^{1}$, I Nyoman Widana ${ }^{2}$, \\ Desak Putu Eka Nilakusmawati ${ }^{3}$ \\ ${ }^{1,2,3}$ Jurusan Matematika FMIPA Universitas Udayana, Bukit Jimbaran-Bali \\ e-mail: ${ }^{1}$ paulalahallo@ rocketmail.com, ${ }^{2}$ nwidana@yahoo.com, \\ ${ }^{3}$ nilakusmawati_desak@yahoo.com
}

\begin{abstract}
This study calculates non renewable monthly premiums and renewable monthly premiums for health insurance. Formulations used in this study were derived from the equations used by Wilandari (2007). The monthly premium calculation uses a CSO mortality table and an interest rate of 6\%. To illustrate the calculating of the premium it is assumed that a family consist of a father, a mother and a son, respectively with age 40, 36 and 9 years old. The results obtained were that the total premium is paid amounted to Rp. 155.02,00 every month for 20 years. Benefit for the cost of room, doctor visits, and the cost of care respectively were $R p$. 200.000,00 per day, $R p$. 75.000,00 per day and $R p$. 4.000.000,00 per periode. Average duration of treatment was 180 days. The renewable monthly premium was paid in different amounts each year, with the range from $R p$. 80.425,00 to $R p$. 406.465,00. From this study, Although initially the renewable premium is cheaper than the non renewable premium, at the end it is more expensive than the non renewable premium. In this study it was obtained too that 12 times the monthly premium is greater than 1 times the annual premium.
\end{abstract}

Keywords: insurance, monthly payment, health insurance

\section{Pendahuluan}

Asuransi kesehatan adalah alat keuangan yang menyediakan dana untuk perawatan rumah sakit anggota asuransi dan keluarganya selama ia tidak mampu bekerja (Ali, [4]). Untuk itu peserta asuransi harus membayar premi. Premi asuransi dapat dibayarkan secara bulanan, kwartalan, semesteran dan tahunan. (Wilandri, [3]) telah melakukan penelitian terhadap asuransi kesehatan yang pembayaran preminya dilakukan secara tahunan.

Penelitian ini mengkaji asuransi kesehatan yang pembayaran preminya dilakukan secara bulanan dengan kontrak premi yang diperbaharui dan yang tidak diperbaharui. Tujuan dari penelitian ini adalah untuk mengetahui perbandingan perhitungan premi bulanan dan tahunan untuk premi yang tidak diperbaharui dengan yang diperbaharui.

\footnotetext{
${ }^{1}$ Mahasiswa Jurusan Matematika FMIPA Universitas Udayana

${ }^{2,3}$ Staf Pengajar Jurusan Matematika FMIPA Universitas Udayana
} 
Untuk menghitung besarnya premi diperlukan tabel mortalitas. Tabel mortalitas yang digunakan dalam penelitian ini adalah RP-2000 Mortality Tabel dan CSO1941. Adapun persamaan-persamaan yang terdapat pada tabel mortalitas antara lain:

$$
\begin{aligned}
& p_{x}=\frac{l_{x+1}}{l_{x}}, \\
& q_{x}=\frac{d_{x}}{l_{x}}, \\
& d_{x}=l_{x}-l_{x+1},
\end{aligned}
$$

dengan $l_{x}$ banyaknya orang yang hidup pada tahun ke- $x, d_{x}$ menyatakan banyaknya orang yang meninggal pada tahun ke- $x, p_{x}$ menyatakan peluang hidup pada tahun ke- $x$, dan $q_{x}$ menyatakan peluang meninggal pada tahun ke- $x$.

Anuitas adalah suatu pembayaran dalam jumlah tertentu, yang dilakukan dalam setiap selang waktu dan jangka waktu tertentu secara berkelanjutan (Futami, [2]). Ada 2 jenis anuitas, yaitu anuitas pasti dan anuitas hidup.

Anuitas pasti tahunan dirumuskan sebagai:

$$
\ddot{a}_{n} \ni \frac{1-v^{n}}{d}
$$

dengan $d=1-v, v=\frac{1}{1+i}$, dan $i=$ suku bunga, sedangkan anuitas pasti bulanan dirumuskan sebagai:

$$
\begin{aligned}
\ddot{a}_{n}^{(m)} & =\frac{1-v^{n}}{d^{(k)}}, \\
\text { dengan } d^{(k)} & =\frac{i^{(k)}}{(1+i)^{\frac{1}{k}}}, \text { dan } i^{(k)}=k\left\{(1+i)^{\frac{1}{k}}-1\right\} .
\end{aligned}
$$

Kemudian anuitas hidup tahunan dirumuskan sebagai:

$$
\ddot{a}_{x: n} \supsetneq \frac{N_{x}-N_{x+n}}{D_{x}},
$$

dengan $D_{x}=v^{x} l_{x}, N_{x}=\sum_{i=0} D_{x+i}$

Penentuan jumlah tanggungan yang diberikan perusahaan asuransi dihitung dengan menggunakan persamaan:

$$
\bar{A}_{x: n}^{1}=v^{\frac{1}{2}} q_{x}+\left(v p_{x}\right)\left(v^{\frac{1}{2}} q_{x+1}\right)+\cdots+\left(v_{n-1}^{n-1} q_{x+1}\right)\left(v^{\frac{1}{2}} q_{x+n-1}\right) .
$$

Persamaan dasar untuk asuransi selama $n$ tahun dengan pembayaran $m$ kali setahun adalah:

$$
m P_{x}{ }^{(m)} \ddot{a}_{x+n}{ }^{(m)}=\bar{A}_{x: n}^{1} .
$$

\section{Penurunan Model}

Pada bagian ini akan dirumuskan model untuk pembayaran premi yang tidak diperbaharui dan yang diperbaharui. Model asuransi kesehatan untuk pembayaran premi yang tidak diperbaharui bagi seseorang berusia $x$ tahun dengan pembayaran premi $m$ kali setahun selama $n$ tahun adalah: 


$$
P^{(m)}=\frac{\sum_{t=0}^{n-1} \bar{D}_{x+t} q_{x}^{s h} T^{s h} B^{s h}}{m\left(\left(N_{x}-N_{x+n}\right)-\frac{m-1}{2 m}\left(D_{x}-D_{x+n}\right)\right)},
$$

dengan $\bar{D}_{x}=v^{x+\frac{1}{2}} l_{x}, q_{x}^{\text {sh }}$ adalah peluang orang terserang penyakit pada saat tahun ke- $x, T^{s h}$ adalah rata-rata jumlah hari perawatan rumah sakit, dan $B^{s h}$ adalah besar benefit.

Selanjutnya model asuransi kesehatan bulanan untuk pembayaran premi yang diperbaharui setiap tahun bagi seseorang berusia $x$ tahun dengan pembayaran premi $m$ kali setahun selama 1 tahun dan premi diperbaharui setiap tahun selama $n$ tahun, adalah:

$$
P^{(m)}=\frac{\bar{D}_{x+t} q_{x+t}^{s h} T^{s h} B^{s h}}{m\left(D_{x+t}-\frac{m-1}{2 m}\left(D_{x+t}-D_{x+t+1}\right)\right)}
$$

Santunan diberikan apabila anggota asuransi dirawat di rumah sakit.

\section{Hasil dan Pembahasan}

\section{Contoh Penerapan}

Misalkan sebuah keluarga yang terdiri dari ayah usia 40 tahun, ibu usia 36 tahun, 1 anak laki-laki usia 9 tahun membeli polis asuransi kesehatan selama 20 tahun dengan santunan Rp200.000,00 per hari untuk biaya kamar dan Rp75.000,00 perhari untuk biaya kunjungan dokter rata-rata 180 hari serta biaya perawatan maksimum per periode rawat inap adalah $\mathrm{Rp} 4.000 .000,00$ dan bunga $6 \%$ per tahun (Allianz, [1]).

\section{a. Premi yang tidak diperbaharui}

Berdasarkan persamaan (10) dan $m=12$ diperoleh premi yang harus dibayar untuk ayah, ibu dan anak setiap bulan selama 20 tahun masing-masing sebesar Rp. 93.966,00 Rp.52.879,00 dan Rp.12.845,00 per bulan. Besar premi tahunan tidak diperbaharui yang harus dibayarkan (Wilandri, [3]) untuk ayah, ibu, atau anak masing-masing adalah: Rp1.092.684,00, Rp550.390,00, dan Rp149.997,00 per tahun. Dari sini diperoleh bahwa 12 kali pembayaran premi bulanan yang tidak diperbaharui lebih besar dibanding dengan 1 kali pembayaran premi tahunan.

Selanjutnya berdasarkan hasil perhitungan premi tahunan (Wilandri, [3]) dan dengan menggunakan persamaan (6), dapat dihitung besar premi yang harus dibayar apabila ayah, ibu atau anak meninggal sebelum masa kontrak habis. Hasil perhitungan ditunjukan pada Tabel 1 . 
Tabel 1. Simulasi Premi Tahunan Tidak Diperbaharui

\begin{tabular}{|c|c|c|c|c|c|c|c|}
\hline \multirow{2}{*}{ Tahun } & \multicolumn{2}{|c|}{ Premi Ayah } & \multicolumn{2}{c|}{ Premi Ibu } & \multicolumn{2}{c|}{ Premi Anak } \\
\cline { 2 - 8 } & $\begin{array}{c}\text { Meninggal } \\
\text { Antara Usia }\end{array}$ & $\begin{array}{c}\text { Jumlah Premi } \\
\text { Yang Terbayarkan }\end{array}$ & $\begin{array}{c}\text { Meninggal } \\
\text { Antara Usia }\end{array}$ & $\begin{array}{c}\text { Jumlah Premi Yang } \\
\text { Terbayarkan }\end{array}$ & $\begin{array}{c}\text { Meninggal } \\
\text { Antara Usia }\end{array}$ & $\begin{array}{c}\text { Jumlah Premi Yang } \\
\text { Terbayarkan }\end{array}$ & 149997 \\
\hline 1 & $40-41$ & 1092684 & $36-37$ & 550390 & $9-10$ & 1793071 \\
\hline 2 & $41-42$ & 2111196 & $37-38$ & 1067102 & 11 & 309330 & 3487628 \\
\hline 3 & $42-43$ & 3065724 & $38-39$ & 1554566 & $11-12$ & 478534 & 5098824 \\
\hline 4 & $43-44$ & 3959891 & $39-40$ & 2012070 & $12-13$ & 658214 & 6630175 \\
\hline 5 & $44-45$ & 4797111 & $40-41$ & 2441320 & $13-14$ & 849046 & 8087477 \\
\hline 6 & $45-46$ & 5580591 & $41-42$ & 2841433 & $14-15$ & 1051771 & 9473795 \\
\hline 7 & $46-47$ & 6313359 & $42-43$ & 3216410 & $15-16$ & 1267187 & 10796956 \\
\hline 8 & $47-48$ & 6998270 & $43-44$ & 3567675 & $16-17$ & 1496110 & 12062055 \\
\hline 9 & $48-49$ & 7638008 & $44-45$ & 3896569 & $17-18$ & 1739354 & 13273931 \\
\hline 10 & $49-50$ & 8235113 & $45-46$ & 4204352 & $18-19$ & 1997871 & 14437336 \\
\hline 11 & $50-51$ & 8791971 & $46-47$ & 4492213 & $19-20$ & 2272623 & 15556806 \\
\hline 12 & $51-52$ & 9310836 & $47-48$ & 4761273 & $20-21$ & 2564699 & 16636808 \\
\hline 13 & $52-53$ & 9793835 & $48-49$ & 5012588 & $21-22$ & 2875200 & 17681623 \\
\hline 14 & $53-54$ & 10242980 & $49-50$ & 5247155 & $22-23$ & 3205376 & 18695511 \\
\hline 15 & $54-55$ & 10660162 & $50-51$ & 5465911 & $23-24$ & 3556518 & 19682592 \\
\hline 16 & $55-56$ & 11047178 & $51-52$ & 5669742 & $24-25$ & 3930038 & 20646958 \\
\hline 17 & $56-57$ & 11405723 & $52-53$ & 5859484 & $25-26$ & 4327409 & 21592616 \\
\hline 18 & $57-58$ & 11737400 & $53-54$ & 6035926 & $26-27$ & 4750300 & 22523627 \\
\hline 19 & $58-59$ & 12043733 & $54-55$ & 6199813 & $27-28$ & 5200415 & 23443961 \\
\hline
\end{tabular}

\section{b. Premi yang diperbaharui}

Berdasarkan persamaan (11) dan mensubstitusikan $m=12$, maka besar premi bulanan yang harus dibayar untuk ayah, Ibu, dan anak dapat dilihat pada Tabel 2.

Tabel 2. Premi Bulanan Diperbaharui

\begin{tabular}{|r|r|r|r|r|r|}
\hline Tahun & Ayah & Ibu & Anak & Total & Dalam Setahun \\
\hline 1 & 48101 & 22900 & 9300 & 80301 & 935939 \\
\hline 2 & 50918 & 24685 & 9433 & 85037 & 991139 \\
\hline 4 & 54184 & 26650 & 9744 & 90578 & 1055721 \\
\hline 5 & 57942 & 28882 & 10145 & 96969 & 1130218 \\
\hline 6 & 67298 & 34510 & 11302 & 113110 & 1217757 \\
\hline 7 & 72137 & 37996 & 11970 & 122103 & 1423163 \\
\hline 8 & 77428 & 41795 & 12638 & 131861 & 1536899 \\
\hline 9 & 83082 & 45910 & 13395 & 142386 & 1659569 \\
\hline 10 & 89144 & 50161 & 14063 & 153367 & 1787562 \\
\hline 11 & 95571 & 54594 & 14731 & 164895 & 1921925 \\
\hline 13 & 109519 & 59210 & 15354 & 184083 & 2145567 \\
\hline 14 & 130529 & 64053 & 15889 & 199265 & 2322517 \\
\hline 15 & 143141 & 74919 & 16602 & 234662 & 2518490 \\
\hline 16 & 162407 & 82821 & 16736 & 261964 & 3053305 \\
\hline 17 & 188342 & 90286 & 16737 & 295365 & 3442608 \\
\hline 19 & 210598 & 98792 & 16827 & 326217 & 3802196 \\
\hline 20 & 266807 & 108565 & 17006 & 362377 & 4223665 \\
\hline
\end{tabular}

Berdasarkan perhitungan didapat premi bulanan yang diperbaharui setiap tahun dibayarkan dalam rentang Rp.80.301,00-Rp. 406.465,00.

Besar premi tahunan diperbaharui (Wilandri, [3]) dan simulasi premi tahunan diperbaharui untuk anggota asuransi yang meninggal sebelum masa kontraknya habis, masing-masing ditunjukkan dalam Tabel 3 dan Tabel 4. 
Tabel 3. Premi Tahunan Diperbaharui

\begin{tabular}{|r|r|r|r|r|}
\hline \multicolumn{1}{|c|}{ Tahun } & \multicolumn{1}{|c|}{ Ayah } & \multicolumn{1}{c|}{ Ibu } & Anak & \multicolumn{1}{c|}{ Jumlah } \\
\hline 1 & 560689 & 267094 & 108604 & 936388 \\
\hline 2 & 593427 & 287879 & 110163 & 991469 \\
\hline 3 & 631360 & 310743 & 113801 & 1055904 \\
\hline 4 & 675010 & 336725 & 118477 & 1130213 \\
\hline 5 & 725934 & 366864 & 124713 & 1217512 \\
\hline 6 & 783614 & 402200 & 131988 & 1317802 \\
\hline 7 & 839735 & 442732 & 139783 & 1422249 \\
\hline 8 & 901052 & 486901 & 147577 & 1535530 \\
\hline 9 & 966527 & 534707 & 156411 & 1657645 \\
\hline 10 & 1036678 & 584073 & 164206 & 1784956 \\
\hline 11 & 1110986 & 635517 & 172000 & 1918503 \\
\hline 12 & 1272593 & 689040 & 179275 & 2140908 \\
\hline 13 & 1385874 & 745161 & 185511 & 2316546 \\
\hline 14 & 1515264 & 805439 & 190187 & 2510891 \\
\hline 15 & 1660763 & 870913 & 193825 & 2725501 \\
\hline 16 & 1883168 & 962369 & 195384 & 3040921 \\
\hline 17 & 2182479 & 1048629 & 195384 & 3426493 \\
\hline 18 & 2438661 & 1146841 & 196423 & 3781925 \\
\hline 19 & 2740051 & 1259602 & 198502 & 4198155 \\
\hline 20 & 3089248 & 1411856 & 204218 & 4705322 \\
\hline
\end{tabular}

Tabel 4. Simulasi Premi Tahunan Diperbaharui

\begin{tabular}{|c|c|c|c|c|c|c|c|}
\hline \multirow[b]{2}{*}{ Tahun } & \multicolumn{2}{|c|}{ Premi Ayah } & \multicolumn{2}{|c|}{ Premi Ibu } & \multicolumn{2}{|c|}{ Premi Anak } & \multirow[b]{2}{*}{ Total } \\
\hline & $\begin{array}{c}\text { Meninggal } \\
\text { Antara }\end{array}$ & $\begin{array}{c}\text { Jumlah } \\
\text { Premi }\end{array}$ & \begin{tabular}{|c|} 
Meningga \\
I Antara \\
\end{tabular} & $\begin{array}{c}\text { Jumlah } \\
\text { Premi }\end{array}$ & \begin{tabular}{|c|} 
Meninggal \\
Antara
\end{tabular} & $\begin{array}{c}\text { Jumlah } \\
\text { Premi } \\
\end{array}$ & \\
\hline 1 & $40-41$ & 560689 & $36-37$ & 267094 & $9-10$ & 108604 & 936388 \\
\hline 2 & $41-42$ & 1154116 & $37-38$ & 554973 & $10-11$ & 218768 & 1927857 \\
\hline 3 & $42-43$ & 1785476 & $38-39$ & 865717 & $11-12$ & 332568 & 2983761 \\
\hline 4 & $43-44$ & 2460486 & $39-40$ & 1202442 & $12-13$ & 451046 & 4113974 \\
\hline 5 & $44-45$ & 3186420 & $40-41$ & 1569307 & & 575759 & 5331485 \\
\hline 6 & $45-46$ & 3970034 & 41-42 & 1971506 & $14-15$ & 707747 & 6649287 \\
\hline 7 & $46-47$ & 4809769 & $42-43$ & 2414238 & $15-16$ & 847529 & 8071536 \\
\hline 8 & $47-48$ & 5710821 & $43-44$ & 2901139 & $16-17$ & 995107 & 9607066 \\
\hline 9 & $48-49$ & 6677347 & $44-45$ & 3435846 & $17-18$ & 1151518 & 11264711 \\
\hline 10 & $49-50$ & 7714025 & $45-46$ & 4019919 & $18-$ & 1315723 & 13049667 \\
\hline 11 & 50-51 & 8825011 & $46-47$ & 4655436 & $19-20$ & 1487723 & 14968171 \\
\hline 12 & 51-52 & 10097604 & $47-48$ & 5344476 & $20-21$ & 1666998 & 17109079 \\
\hline 13 & $52-53$ & \begin{tabular}{|l|}
11483479 \\
\end{tabular} & $48-49$ & 6089637 & $21-22$ & 1852509 & 19425625 \\
\hline 14 & $53-54$ & 12998743 & $49-50$ & 6895076 & $22-23$ & 2042697 & 21936515 \\
\hline 15 & $54-55$ & 14659506 & $50-51$ & 7765989 & $23-24$ & 2236522 & 24662016 \\
\hline 16 & $55-56$ & 16542674 & $51-52$ & 8728358 & $24-25$ & 2431906 & 27702938 \\
\hline 17 & $56-57$ & 18725153 & $52-53$ & 9776988 & $25-26$ & 2627289 & 31129430 \\
\hline 18 & $57-58$ & 21163814 & 53-54 & 10923829 & $26-27$ & 2823713 & 34911355 \\
\hline 19 & 58-59 & 23903865 & $54-55$ & 12183431 & $27-28$ & 3022214 & 39109510 \\
\hline
\end{tabular}

Berdasarkan Tabel 2 dan Tabel 3 diperoleh bahwa 12 kali pembayaran premi bulanan diperbaharui lebih besar dibanding dengan 1 kali pembayaran premi tahunan diperbaharui. Perbandingan besar premi bulanan yang tidak diperbaharui dan premi bulanan diperbaharui dapat dilihat pada Gambar 1.

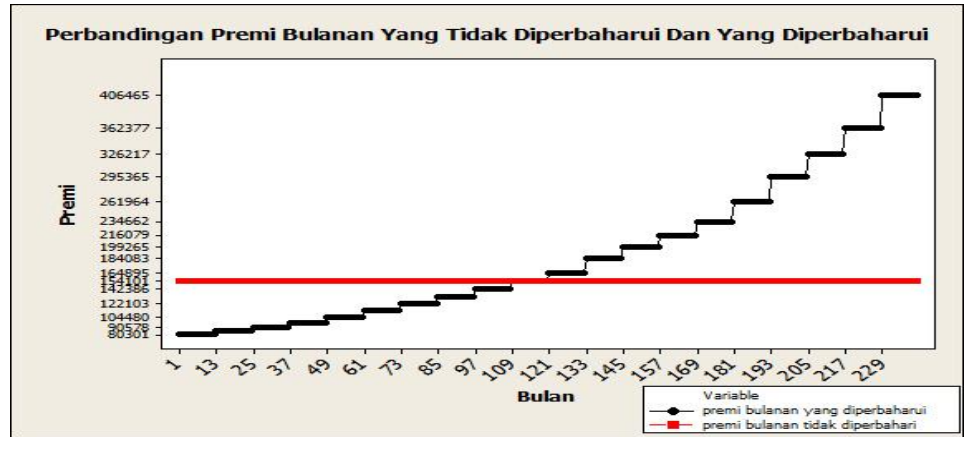

Gambar 1. Besar Premi Bulanan yang Diperbaharui dan Premi Bulanan Tidak Diperbaharui

Berdasarkan Gambar 1, tampak bahwa pada awalnya premi yang diperbaharui lebih murah dari pada premi yang tidak diperbaharui namun setiap tahun terjadi peningkatan, sehingga dari tahun ke 11 hingga tahun ke 20 premi yang diperbaharui lebih besar dibanding dengan premi yang tidak diperbaharui. Nilai tunai premi bulanan yang diperbaharui dengan yang tidak diperbaharui diperoleh bahwa total premi yang dibayarkan sampai kontrak habis secara berturut-turut adalah Rp21.893.452,00 dan Rp22.727.151,00

Simulasi premi tahunan yang diperbaharui dan yang tidak diperbaharui untuk anggota asuransi jika meninggal sebelum masa kontraknya habis ditunjukan pada Gambar 2. 


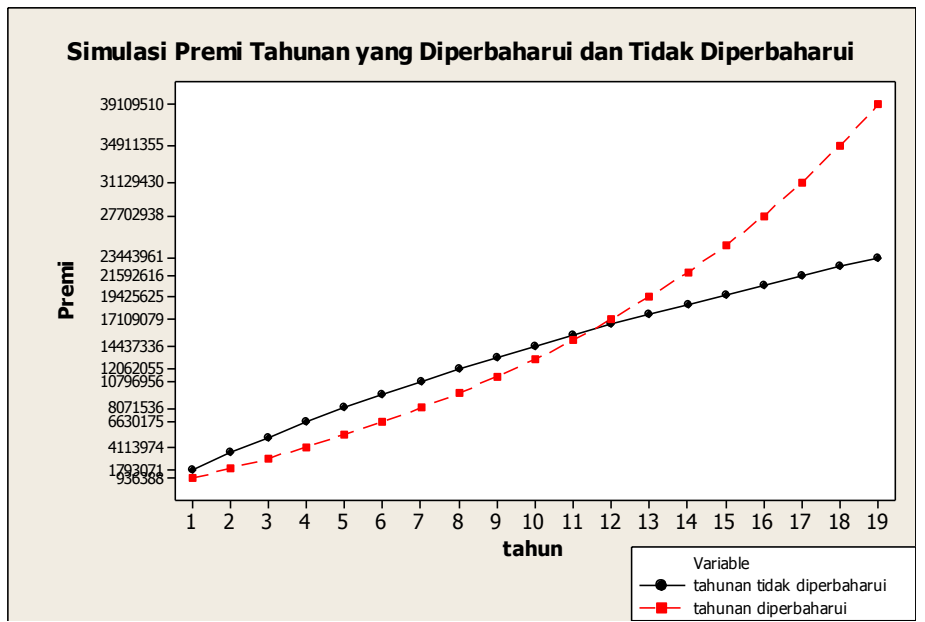

Gambar 2. Simulasi Besar Premi Tahunan yang Diperbaharui dan Premi Tahunan Tidak Diperbaharui

Berdasarkan Gambar 2, pada awal simulasi premi tahunan yang diperbaharui lebih murah dari pada premi yang tidak diperbaharui namun setelah tahun ke 12 premi tahunan yang tidak diperbaharui lebih murah dibanding premi tahunan tidak diperbaharui.

\section{Kesimpulan}

Kesimpulan yang didapat dari penelitian ini adalah:

1. Untuk pembayaran premi yang diperbaharui tiap tahunnya, pada awalnya premi yang diperbaharui tiap tahun lebih murah dari premi yang tidak diperbaharui, tetapi di akhir periode, premi yang diperbaharui lebih mahal dari premi yang tidak diperbaharui.

2. Perbandingan antara premi bulanan yang diperbaharui dan yang tidak diperbaharui dengan premi tahunan yang diperbaharui dan yang tidak diperbaharui adalah: 12 kali pembayaran premi bulanan lebih besar dari 1 kali pembayaran premi tahunan.

\section{Daftar Pustaka}

[1]. Allianz. Brochur Smart health Maxi Violet. http://www.allianz.co.id/AZLIFE/Indonesian/Products/Health+Insurance+In donesia/SmartHealth+Asuransi+Kesehatan.htm (diakses tanggal $22 \mathrm{Mei}$ 2013)

[2]. Futami, T., (1993). Matematika Asuransi Jiwa. (G. Herliyanto, Trans.) Tokyo: The Research Institute Of Life Insurance Welfare, Japan.

[3]. Wilandari, Y., 2007. Asuransi Kesehatan Individu Perawatan Rumah Sakit. Jurnal Matematika. pp. 73-78.

[4]. Ali, A. Hasyim. 1999. Bidang Usaha Asuransi, Bumi Aksara, Jakarta. 